\title{
UNA AMISTAD LITERARIA: TABLADA Y LÓPEZ VELARDE
}

Ya en borrador esta nota sobre José Juan Tablada y Ramón López Velarde, nos llegó noticia de un trabajo de J. M. González de Mendoza sobre la misma amistad literaria ${ }^{1}$. Por lo tanto, no insistimos en algunos datos que ese excelente crítico da a conocer, y nos proponemos tan sólo completar un poco su trabajo, ofreciendo unas cuantas precisiones nuevas sobre las relaciones que unieron a los dos poetas. Si bien la obra de Tablada se diferencia notablemente de la de López Velarde, diecisiete años menor que él, veremos cómo, en el fondo, quizá no estuvieron tan alejados estéticamente el uno del otro como podría creerse. Por lo demás, la cuestión de la influencia de López Velarde sobre la poesía de Tablada en su etapa final no deja de ser un caso curioso de cómo se impone poco a poco el ascendiente de un escritor joven sobre otro ya formado, y autor de una obra ampliamente reconocida.

\section{Tablada y López Velarde:}

su situación histórica

Aunque los gustos actuales tienden injustamente a olvidar un poco la poesía de Tablada, mientras que la de López Velarde cobra un relieve cada vez más perdurable y actual, los dos escritores ocupaban con Enrique González Martínez un lugar, si no parecido, por lo menos complementario en cierto momento del desarrollo histórico de la poesía mexicana moderna. Al desintegrarse el Ateneo de México, en medio del período más violento de las guerras civiles que siguieron a la Revolución de 1910, fueron ellos, seguramente, los poetas que más influyeron (de modo diferente, desde luego) en la orientación de los jóvenes que iniciaban su carrera literaria hacia aquellos años. Es difícil imaginar dos poetas más distintos que González Martínez y Tablada: el uno siempre atento a la unidad interior, austero en su labor literaria; el otro más bien inquieto, y acogedor de todas las novedades poéticas. Ambos, sin embargo, se formaron en el modernismo para luego modificar esta herencia, des-

1 J. M. GonzÁlez de Mendoza, "Tablada y López Velarde", Rueca, núm. 20 (Invierno 1951-1952), pp. 41-47. 
pojándose cada uno, de manera diferente, de sus cualidades más superficiales. Tablada fue el poeta más intranquilo de toda la época: dispuesto siempre a probar y asimilar todo lo más novedoso, sus viajes exóticos, desde el Japón hasta el París de vanguardia, emprendidos con curiosidad febril e incansable, le hicieron aceptar la influencia de las últimas corrientes y modas estéticas. Por esta inquietud artística se abrió a todos los vientos y experimentó la fascinación del viaje y de lo pasajero ${ }^{2}$. Sin inmovilizarse nunca, creó una obra en perpetua transformación, e introdujo oportunamente en la lírica mexicana ciertas formas poéticas de vanguardia. Es natural, pues, que un espíritu como el suyo haya influido en los escritores jóvenes de aquel entonces. Sin embargo, su misma inconformidad y el culto que rendía a las modas del momento constituyen un grave escollo para su obra: una poesía como la suya, indefectiblemente matizada por lo transitorio, acaba por quedar demasiado circunscrita, demasiado limitada. Afortunadamente, a Tablada lo salvó su auténtico temperamento artístico, gracias al cual logró dejarnos un puñado de poemas de intensa emoción y belleza. Salvo algunas notables excepciones (Villaurrutia, González de Mendoza, Octavio Paz), nos parece que la crítica actual suele pasar en silencio el gran estímulo que debe haber ejercido la obra de Tablada hacia la segunda década de este siglo ${ }^{3}$ Si su poesía no ha resistido tal vez la prueba del tiempo, es evidente que en su época sí rejuveneció ciertos aspectos de la lírica mexicana (baste pensar en cómo llegó a dar libertad a la metáfora, conforme a las más avanzadas teorías europeas de vanguardia). No fue Tablada un poeta a la altura de González Martínez ni de López Velarde, pero su influencia, tan diversa de la de éstos y no tan duradera, fue necesaria -y provechosa- para muchos que buscaban nuevos derroteros expresivos en esos años de transición que van desde el Ateneo hasta la generación que iba a agruparse en torno a la revista Contemporáneos.

Habían realizado ya una porción considerable de su obra González Martínez y Tablada, cuando llegó de la provincia Ramón López Velarde para iniciar una nueva aventura lírica. Hay entre López Velarde y los dos poetas mayores ciertos innegables puntos de contacto: con Tablada comparte un ardiente anhelo de renovación, de novedad; con González Martínez, un impulso de evolución interior, de

2 Véase el medular estudio de Octavio Paz, "Estela de José Juan Tablada", en su libro Las peras del olmo, México, 1957, pp. 78-79.

3 Xavier Villaurrutia, La poesía de los jóvenes de México, México, 1924, p. 12, escribe acerca de Ios tres poetas: "Si Enrique González Martínez era, hacia 1918, el dios mayor y casi único de nuestra poesía; si de él partían las inspiraciones..., necesitábamos nuevamente de Adán y de Eva que vinieran a darnos con su rebelión, con su pecado, una tierra nuestra de más amplios panoramas, de mayores libertades; una tierra que ver con nuestros propios ojos. La fórmula será: Adán y Eva=Ramón López Velarde y José Juan Tablada". 
exploración hacia dentro, y una ejemplar seriedad artística. Por lo demás, pese a sus rasgos diferenciadores, la crítica más autorizada ha visto en González Martínez y López Velarde las más claras raíces de la poesía mexicana contemporánea ${ }^{4}$. Casi todos los que vinieron después les deben, en una o en otra forma, fecundas sugestiones poéticas. Sin embargo, López Velarde se diferencia de González Martínez por haber creado un nuevo lenguaje, tan atrevido y tan personal. Y asimismo, su tentativa poética queda lejos de la ruta más exterior, exótica y pintoresca de Tablada. Éste carece de la profundidad del poeta zacatecano; su estilo es menos auténtico y más rebuscado; a cierta lentitud contemplativa de López Velarde se contrapone la prisa ansiosa que tiene Tablada por saborearlo todo. Finalmente, a diferencia de José Juan Tablada y de Enrique González Martínez, Ramón López Velarde no pasó por una etapa propiamente modernista.

En una obra tan breve como intensa, López Velarde no se detiene nunca en las superficies. Su trayectoria de poeta presenta, en rápida síntesis, dos vertientes: una subjetiva y otra más bien objetiva; la primera lleva hacia lo interior de su alma; la segunda, hacia lo más esencial de su circunstancia mexicana. López Velarde ahonda dramáticamente en lo más entrañable de su propio ser angustiado; y cuando se exterioriza un poco, ahonda en la médula de su patria, para evocarla no en lo que tiene sólo de típico, sino en toda su más recóndita intimidad. (Desde luego, la vertiente objetiva es sólo una cuestión de medida, y no supone un abandono de su actitud esencialmente lírica.)

Primer encuentro. Una curiosa anécdota literaria

Pedro de Alba recuerda cómo en 1912 llegó López Velarde a la capital y cómo, a instancias de Balbino Dávalos, le llevó a conocer a José Juan Tablada en "su casa de Churubusco". Tablada -prosigue Pedro de Alba- había publicado anteriormente un poema de López Velarde, "A la gracia primitiva de las aldeanas", en la página literaria de El Imparcial, presentando al autor como "poeta español". Cuando el propio Pedro de Alba le hizo notar su error, Tablada explicó que había encontrado en el poema "un sabor muy castizo, y que al no tener referencias precisas sobre el autor, lo creyó español", tras lo cual, dirigiéndose a López Velarde, añadió: "Sus versos

4 Jaime Torres Bodet, "Perspectiva de la literatura actual (1915-1928)", Contemporáneos, 2 (1928), núm. 4, pp. 9-10. Véase una opinión más reciente sobre el mismo tema en el artículo de José Lurs MarTínez, "La poesía mexicana contemporánea", NacM, 29 de septiembre de 1946, y otros trabajos posteriores del mismo crítico. 
son mejores que los que escriben los poetas peninsulares de hoy" 5 . La anécdota no carece de gracia, pero es preciso aclarar algunos detalles.

Al mismo asunto se refiere González de Mendoza en su artículo antes citado (pp. 44-45). Recuerda que Tablada fue jefe de redacción de El Imparcial desde principios de enero hasta finales de julio de 1913 , y ofrece precisiones sobre los que le sucedieron en ese cargo. Declara a continuación que ha examinado las colecciones del periódico, de 1912 a 1914 , sin poder encontrar la aludida poesía, y habla con justa indignación de las muchas mutilaciones que sufren los volúmenes guardados en la Hemeroteca Nacional, lamentable vandalismo que dificulta en no pequeña medida la tarea del investigador.

Ahora bien: lo que ocurre es que la poesía en cuestión se publicó en El Imparcial -con algunas variantes que no es del caso señalar en este momento- en el suplemento dominical del día 19 de junio... de 1910. No hay ninguna constancia de que fuera Tablada quien la hizo publicar ni tampoco existe la nota de presentación a que se refiere Pedro de Alba. Sin embargo, es curioso que la poesía de López Velarde esté incluida en la sección de "Literatura Extranjera" de ese suplemento (p. 22), lo cual puede interpretarse, muy verosimilmente, como una prueba de que al autor se le tomó por "poeta español". Tablada no era a la sazón jefe de redacción, pero colaboraba con cierta frecuencia en el periódico hacia 1910. (Según parece, fue en 1911 cuando emprendió su viaje a París, para permanecer allí unos pocos meses). En cuanto al ensayo de Pedro de Alba, su importancia consiste en que nos revela los comienzos de una amistad duradera entre los dos poetas, el uno apenas principiante, el otro dueño ya de cierta categoría literaria ${ }^{6}$.

5 Pedro de Alba, "Ramón López Velarde, el provinciano en la capital", en su libro Ramón López Velarde. Ensayos, México, 1958, pp. 23-35. (En realidad, la casa de Tablada, según me informa J. M. González de Mendoza, estaba en Coyoacán, no en Churubusco).

6 Es posible que esta publicación de "A la gracia primitiva de las aldeanas" en El Imparcial haya sido la primera; pero nuestra hipótesis es provisional, ya que muy a menudo los periódicos de la capital reproducían poemas de López Velarde publicados anteriormente en revistas o periódicos de provincia. Hasta ahora, nadie había advertido que ese poema se imprimió en El Imparcial en junio de 1910. Sin embargo, Luis Noyola Vázquez, "Primera edición frustrada de La sangre devota, 1910", México en el Arte, núm. 7 (Primavera de 1949), pp. 30-37, publica una versión del mismo poema, lo cual comprueba que es de 19 io o un poco anterior. Noyola observa la variante ensueños (por empeños) en el verso 27 . En la versión de $E l$ Imparcial y en la que pasó a La sangre devota (1916) no existe la dedicatoria a Luis Rosado Vega que aparece en la reproducida por Noyola. Hay otras variantes en el texto de El Imparcial: una inversión en las primeras estrofas, ciertos cambios de preposición, y la palabra muchachas en el último verso (en el texto definitivo, doncellas). 
La verdadera presentación

de López Velarde por Tablada

No es un hecho desconocido que López Velarde recibió el espaldarazo de manos de Tablada en una crónica publicada en 1914 ("Versos de Augusto Genin; Prosas de Efrén Rebolledo; Un nuevo poeta", El Mundo Ilustrado, 7 de junio de 1914). Tablada, según refiere él mismo, recibió una carta de López Velarde, con la cual le enviaba varios poemas manuscritos, y eligió, para reproducirlo en su columna de El Mundo Ilustrado, el soneto "Del pueblo natal", publicado ya en Guadalajara en 1912, y que pasaría sin variantes a La sangre devota. (Dicho sea de paso, la reproducción que hace Tablada de ese soneto es posterior a las otras dos únicas colaboraciones de López Velarde que llegaron a publicarse en la misma revista: el 15 de junio de 1913 apareció, con el título "Para una dama" y alguna otra leve variante, el poema que más tarde se incluiría en La sangre devota con el título "Mientras muere la tarde"; y el 12 de octubre de 1913, el cuento "El obsequio de Ponce", recientemente exhumado del olvido por el crítico y poeta Francisco González Guerrero). He aquí la parte más sustanciosa del breve comentario de Tablada sobre los versos del poeta joven - de los cuales prometió ocuparse en otro artículo que nunca llegó a publicarse, a causa del destierro que pronto lo llevaría a Nueva York:

Y sigo leyendo otros versos del mismo autor [López Velarde], con la creciente sensación de encontrar un nuevo astro que se revela con sencillas músicas y fragancias encantadoras. Son los versos de López Velarde, flores de prados campesinos, claveles de macetas que abriéndose sobre los viejos tiestos de Talavera, arden entre la penumbra de nuestros hondos corredores coloniales. Su perfume recuerda el aroma que exhalan los herbarios del divino Francis Jammes.

Conviene recordar también que en La sangre devota, donde López Velarde recogió sus poemas compuestos en los años de 1908 a 1915 , se halla una hermosa composición, "Me despierta una alondra...", dedicada a José Juan Tablada. No hemos podido determinar el lugar de la primera publicación de esta poesía, lo cual nos ayudaría a fecharla; pero en vista de su forma (combinación irregular de heptasílabos y alejandrinos) y de cierta sensualidad en ciernes, no desligada todavía del fondo provinciano, nos parece posible que sea precisamente del mismo año del espaldarazo literario que Tablada dio al joven poeta desde las columnas de El Mundo Ilustrado. Seguramente es de la última cosecha, de 1914 o de 1915 , cuando López Velarde ordenaba el material de su primer libro. 


\section{López Velarde habla de Tablada (rgr7)}

En 1914 López Velarde se radica definitivamente en la capital, y un poco después Tablada sale desterrado para Nueva York, donde permanecerá hasta 1918. Durante esta ausencia, López Velarde se ocupa con cierta extensión y en términos muy elogiosos de la obra en verso y en prosa de Tablada, en una crónica publicada en la revista Pegaso, que dirigían en un principio González Martínez, Efrén Rebolledo y el propio López Velarde ("Poesía y estética", Pegaso, núm. 16,28 de junio de 1917, p. 3). Por cierto que esa crónica es muy importante también en otro sentido: revela en forma muy expresa la simpatía que despertaba en López Velarde la obra poética de los escritores más jóvenes (uno de los que allí se mencionan es Carlos Pellicer), relación amistosa con la nueva generación que el poeta de La sangre devota reafirmaría más tarde al hacer una presentación de José Gorostiza y Bernardo Ortiz de Montellano desde las páginas de El Universal, el 24 de agosto de 1919. En cuanto a José Juan Tablada, López Velarde ve en él "una de las más severas aristocracias" de la poesía mexicana, alaba su temperamento literario, le agradece las colaboraciones - prosas y versos- que ha enviado a la revista Pegaso desde su destierro de Nueva York, recuerda la visita que le hizo en 1914 en su casa de Coyoacán, acompañado por Villalpando, y termina con estas palabras:

La producción del autor del divulgado Onix va en derechura a la estética. Sus disciplinas estéticas son ineludibles, enérgicas, crueles, inhumanas. Por eso la alcurnia de Tablada es una alcurnia esotérica, de horca y cuchillo. Sus palabras, en verso o en prosa, aguijonean a los lectores del feudo, entorpecidos en los menesteres de clerecía y juglaría...7

Esto nos muestra que ya en 1917 encontraba López Velarde en el lenguaje literario de Tablada la razón de su novedad; y precisamente ese afán de renovación los guiaba a los dos, por caminos distintos, hacia un nuevo instrumento expresivo.

Un importante intercambio de cartas $(1919)^{8}$

El 18 de junio de 1919, cuando Tablada reside en Caracas, López Velarde le dirige una carta que constituye un documento muy

7 Nuestra cita procede de $E l$ don de febrero y otras prosas, prólogo y recopilación de Elena Molina Ortega, México, 1952, pp. 310-312. Pero la fecha de publicación que da la recopiladora está equivocada, y sus datos bibliográficos son incompletos.

8 En el mismo año de la publicación de Zozobra, Tablada volvió a ocuparse de López Velarde en un trabajo publicado el 17 de marzo de 1919 en El 
revelador. La parte más significativa es la que expone la actitud de reserva y de duda que el autor de La sangre devota tiene ante la poesía ideográfica que hacia entonces ensayaba Tablada. Por lo demás, nos hace ver los conocimientos que tenía ya de la poesía francesa más novedosa, y la fundamental seriedad con que concebía el quehacer literario. He aquí sus palabras:

...Mi actitud, en suma, es de espera. Hasta hoy, lo ideográfico me interesa, más que por sí mismo, por usted que lo cultiva. Desde que conocí lo de Apollinaire, se me quedó la impresión de algo convencional, y esa impresión persistió después de reproducirse aquí los poemas de usted en La Habana: "Los ojos de la máscara" me iluminarán seguramente, ayudándome a concluir mi criterio. Hoy por hoy, dudo con duda grave de que la poesía ideográfica se halle investida de las condiciones serias del arte fundamental. La he visto como una humorada, capaz, es claro, de rendir excelentes frutos si la ejercita un hombre de la jerarquía estética de usted. De cualquier modo, le repito que sabré estar a su lado, con mi convicción de que la prosapia de su musa es una garantía permanente de respetabilidad, aun en los procedimientos más desusados de la belleza...9

Nos parece sumamente valioso este documento por la manera como en él se contraponen la estética seria y meditada de López Velarde y esa impaciencia de Tablada a que antes aludíamos, ese afán suyo de probar todo lo más nuevo que podían ofrecerle las corrientes de vanguardia. López Velarde reconoce que no es frivolidad lo que induce a su amigo a experimentar con formas nuevas, sino la convicción de que el arte moderno es un arte dinámico, en constante evolución y movimiento; pero teme que esos experimentos se queden en "algo convencional", que no pasen de una "humorada", y se mantiene en una actitud de espera y de "duda grave".

Igualmente importante es la respuesta de Tablada a López Velarde, que quizá el mismo destinatario hizo publicar en El Universal Ilustrado (núm. 132, 13 de noviembre de 1919, p. 23). De ella copiamos con cierta extensión algunos fragmentos, no sólo por ser muy poco conocida, sino porque Tablada hace allí una notable defensa y exégesis de sus procedimientos poéticos. Alude primero a las

Tiempo Nuevo de Bogotá. Tomamos el dato de una carta de Tablada al presidente Venustiano Carranza (10 de noviembre de 1919), en la cual hace una relación de sus trabajos de propaganda política y cultural en pro de México. Reproduce esa carta Nina Cabrera de Tablada, José Juan Tablada en su intimidad, México, 1954, pp. 120-131. No nos ha sido posible hasta ahora ver el artículo de Tablada, que seguramente tiene mucho interés para el estudio de estas relaciones literarias.

9: Carta reproducida en Ramón López Velarde, Poesias, cartas, documentos e iconografia, pról. y recopil. de Elena Molina Ortega, México, 1952, pp. 75-77. 
composiciones suyas que ha leído López Velarde, calificándolas de simples "avant-coureurs" de su próximo volumen, Los ojos de la Máscara; los poemas actuales, los que ahora escribe - prosigue Tablada-, representan un gran progreso sobre los ideográficos que compuso antes en Nueva York:

[Mis últimos poemas] son un franco lenguaje; algunos no son simplemente gráficos sino arquitectónicos... Y todo es sintético, discontinuo y por tanto dinámico; lo explicativo y lo retórico están eliminados para siempre; es una sucesión de estados sustantivos; creo que es poesía pura... Lo que me dice de la ideografía me interesa y me preocupa. Le parece a usted convencional... ¿más convencional que seguir expresándose en odas pindáricas, y en sonetos, como Petrarca?.. . La ideografía tiene, a mi modo de ver, la fuerza de una expresión "simultáneamente lírica y gráfica", a reserva de conservar el secular carácter ideofónico. Además, la parte gráfica substituye ventajosamente la discursiva o explicativa de la antigua poesía, dejando los temas literarios en calidad de "poesía pura", como lo quería Mallarmé. Mi preocupación actual es la síntesis, en primer lugar porque sólo sintetizando creo poder expresar la vida moderna en su dinamismo y en su multiplicidad...

Si usted, mi querido amigo, no fuera tan grande poeta, si en sus obras no manifestara un ejemplo tan encantador de liberación personal, tomaría a mal esa frase suya: "Dudo que la poesía ideográfica se halle investida de las condiciones serias del arte fundamental". Esas condiciones y ese arte, ¿no serán, en último análisis, el respeto a la tradición que nos abruma, nos iguala, impidiendo con la tiranía de sus cánones, la diferenciación artística de las personalidades?...

Más bien creo, y me lo confirma su actitud espectante, en que aún no tiene usted documentación abundante para hacer un juicio definitivo. Además, mi poesía ideográfica, aunque semejante en su principio a la de Apollinaire, es hoy totalmente distinta; en mi obra el carácter ideográfico es circunstancial, los caracteres generales son más bien la síntesis sugestiva de los temas líricos puros y discontinuos, y una relación más enérgica de acciones y reacciones entre el poeta y las causas de la emoción... Mis libros "Un día" y "Li-Po" le explicarán mis propósitos mejor que esta exégesis prematura...

Estas líneas de Tablada, escritas en el verano o el otoño de 1919 , ponen de manifiesto la razón por la cual se le reconoció siempre un lugar tan destacado en la vanguardia poética. Las observaciones que hace sobre la "construcción" de sus poemas y la necesidad de formas sintéticas, que le permitan captar la vida moderna en toda su dinámica multiplicidad, traen ciertamente un eco de las estéticas de postguerra que circulaban por esas fechas en Europa. Es explícita su actitud ante las convenciones literarias, así como el afán de eliminar 
lo retórico y discursivo de su obra poética, todo lo cual nos exime de comentario.

De nuevo habla López Velarde

sobre Tablada (1920)

En una prosa fechada en marzo de 1920, López Velarde vuelve a ocuparse de su amigo $^{10}$. Es también un documento valioso, que rebasa el mero elogio y apreciación cordial de la obra y la personalidad literaria de Tablada y ofrece agudas precisiones sobre el concepto que el propio López Velarde tenía del arte. Comienza por negar que Tablada sea un poeta frívolo, amigo de adoptar simplemente las modas pasajeras del día, e insiste luego en la verdadera emoción (a veces ignorada) que no deja de palpitar en sus versos, desde los primeros que compuso hasta los más recientes. Reconoce que $A l$ sol y bajo la luna tiene páginas no bien logradas (al lado de otras excelentes), pero en cambio califica a $U n$ dia de "libro perfecto", y señala en él la presencia de dos virtudes que López Velarde exaltaba siempre dondequiera que las descubría: "medula vital" y "la victoria que las modalidades expresivas consiguen sobre la crasa dicción de la ralea". Precisa también su propia actitud ante este poeta "de arte eximio", envidia de los "cenáculos europeos" más maduros, aunque no siempre bien comprendido por los lectores a causa de la constante renovación que caracteriza sus rutas poéticas:

...Extravagancia, declaran algunos. Es posible. Por lo que a mi toca, me sostengo curioso, oliendo la pólvora sin humo del portalira y haciendo votos porque el tema de la excentricidad no ciegue a los visitantes del laboratorio ni los encolerice. Nada más amargo que tratar a empellones los asuntos del espíritu.

10 Desconocemos el lugar y la fecha de primera publicación de esta prosa. Que nosotros sepamos, no se publicó en marzo ni en mayo de 1920 en la Revista de Revistas, según se ha afirmado. Lo único que nos consta es que se reprodujo en la misma revista, años después de la muerte de López Velarde (Revista de Revistas, XXVI, núm. 1,390, 10 de enero de 1937), en un número de homenaje a Tablada, con ocasión de su regreso a la patria después de largos años de ausencia. El motivo indudable del artículo de López Velarde (no recogido hasta ahora en volumen) fue el retorno - pasajero- de Tablada a México en febrero de 1920. De la misma época datan las famosas lecturas que hizo López Velarde, una de ellas en presencia del propio Tablada y de otros amigos en el Hotel Regis, del poema "El sueño de los guantes negros", el cual quedó trunco después de su muerte por razones que no es del caso referir ahora. (Sobre la suerte de esa composición, cf. Manuel Horta, "Juicios sobre Ramón López Velarde", El Universal, 22 de junio de 1924; Enrigue Fernández Ledesma, "Anecdotario de Ramón López Velarde", ibidem; J. M. González de Mendoza, "Añorando a López Velarde", Revista de Revistas, 23 de junio de 1946, y el artículo cit. supra, nota 1 ). 
Estos pintorescos y personalísimos modos de decir - y hay otros casos más extremados en la prosa que nos ocupa- ocultan bajo su tono juguetón un propósito de profunda seriedad, y no es difícil extraer de ellos ciertos conceptos fundamentales, intimamente relacionados con la estética creadora de López Velarde. Leamos, por ejemplo, cómo intenta aquí hacer una definición de la Poesía - de la Poesía con mayúscula:

Ciertamente, la Poesía es un ropaje; pero ante todo, es una substancia. Ora celestes éteres becquerianos, ora tabacos de pecado. La quiebra del Parnaso consistió en pretender suplantar las esencias desiguales de la vida del hombre con una vestidura fementida. Para los actos trascendentales -sueño, baño o amor-, nos desnudamos. Conviene que el verso se muestre contingente, en parangón exacto de todas las curvas, de todas las fechas: olímpico y piafante a las diez, desgarbado a las once; siempre humano. Tal parece ser la pauta de la última estética, libre de los absolutismos de la perfección exterior.

A otras prosas más conocidas que ésta asoman con frecuencia las mismas ideas sobre la esencia de la poesía. No es sólo que a las puras excelencias formales (modernismo) oponga López Velarde la profundidad y la autenticidad de las vivencias (postmodernismo), sino que rechaza, además, los abusos lingüísticos que suponen un lamentable divorcio entre "palabra" y "emoción". Enemigo del preciosismo (del "industrialismo" de la palabra, como él dice), la mayor preocupación de López Velarde fue la adecuación fiel y total de la palabra al sentimiento lírico que fatalmente se sentía llamado a expresar. El lenguaje, para él, no era el fin último, sino el único modo factible de objetivar sus auténticas preocupaciones espirituales. De lo cual se sigue que ciertas audacias y rarezas de López Velarde no son ni tan raras ni tan caprichosas, sino más bien expresiones naturales y legítimas, desde el momento en que las vemos en relación con sus ideales estéticos.

\section{Epílogo}

En 1921, otra vez en Nueva York, José Juan Tablada escribe su conocido "Retablo a la memoria de Ramón López Velarde", poema que es, indudablemente, uno de sus grandes aciertos líricos. Con una emoción hermosa y genuina, se combina en él la intencionada adaptación al tono y a la manera del amigo recién desaparecido. González de Mendoza ha señalado atinadamente en algunas de sus estrofas una clara imitación de "La suave Patria" (art. cit., pp. 41 y 43-44). Pero esa gran elegía no fue la única expresión del dolor que sintió Tablada ante la muerte del joven poeta. El mismo 
González de Mendoza (pp. 41-42) transcribe fragmentos de una carta dirigida a Rafael López el 2 de agosto de 1921, que desborda en expresiones de admiración por la obra de López Velarde y de aflicción por su muerte prematura. "La suave Patria" - dice Tablada en esa carta - lo ha conmovido no sólo "como obra maestra, sino como una reliquia que llevara el sudor de la agonía"; y agrega: "QQué clarividencia doble, de moribundo y de gran poeta! Tiene el ritmo de sus últimos pasos sobre la tierra" 11. Y Fernández Ledesma, citando seguramente otra carta de Tablada, transcribe esta frase que alude al mismo poema: "QQué manera de estrangular la Retórica en el corazón de la Epopeya!" 12

Hay otra carta interesante, del 10 de septiembre de 1922, dirigida también a Rafael López, el cual, según parece, había invitado a Tablada a releer "La última odalisca", uno de los poemas más hermosos -y más herméticos- de López Velarde. Esta relectura produce en Tablada una reacción de gran entusiasmo, de que dan testimonio las líneas siguientes:

¿Qué poeta, qué pasmosa simultaneidad de cerebro y corazón, cómo supo hacer que convergieran el pasado y el futuro en los latidos de su corazón! Ése fue un arcángel, un serafín de Dios, que cayó un instante a la tierra y rebotó sobre nuestro barro con ímpetu tal que se nos fue. Allá nos espera, y será indudablemente quien dé la bienvenida a nuestras conciencias descarnadas... iImagínate qué fiesta, toda música, toda perfume, toda luz y... toda certidumbre! 13

Mucho se ha hablado sobre la influencia de López Velarde en Tablada, especialmente en las poesías de La feria (1928), llenas de notas brillantes de mexicanismo. Esta cuestión queda ya fuera de los límites del presente artículo. Sólo quisiéramos llamar la atención sobre las diferencias que separan a los dos poetas en su manera de ver a México. La visión de López Velarde va hacia dentro, es más intima, más lírica (y más meditada: recuérdese que llegó a exponer toda una teoría sobre ese tema en una prosa, "Novedad de la patria", recogida en $E l$ minutero). Tablada es hombre de temperamento diferente, y al evocar a la patria la ve en sus aspectos exteriores, alegres y más típicos. No pretendemos, sin embargo, negar la mencionada influencia. Existe un testimonio explícito del profesor Torres Rioseco acerca del estímulo que la obra de López Velarde ejerció sobre la poesía "mexicanista" de Tablada:

11 Apud Nina Cabrera de Tablada, op. cit., p. 176.

12 Enrique Fernández Ledesma, "Ramón López Velarde. Boceto de crítica", Revista de Revistas, núm. 1,362, 21 de junio de 1936.

13 Apud Nina Cabrera de Tablada, op. cit., p. 181. 
...Por 1921 López Velarde es su poeta predilecto, y en las estrofas de ese tiempo se intensifica su mexicanismo, aunque remotamente, objetivamente. En la lectura de Zozobra pasamos largos días, Tablada y yo, en Nueva York, y entonces comprendí que en lo exótico de El jarro de flores había mucho de actitud y que Tablada era tan mexicano como López Velarde ${ }^{14}$.

No ha sido nuestra intención, en estas páginas, valorar la obra de Tablada y de López Velarde, sino sencillamente trazar, en orden cronológico, las líneas generales de una duradera amistad literaria. Esperamos haber demostrado el afecto y admiración mutuos que unieron a los dos poetas, quienes, a pesar de sus marcadas diferencias de inspiración y de tono, representaron un saludable intento de renovación y de libertad en cierto momento de la poesía mexicana moderna. Con sus excelencias y sus defectos, ambos legaron a la lírica de su país nuevas posibilidades que fueron desarrolladas, en proporción variable, por muchos poetas que vinieron después. Sin embargo, no creemos aventurado afirmar que la voz de Ramón López Velarde es la que mejor ha resistido al tiempo, la que conserva su actualidad en la poesía de las últimas generaciones.

The University of Chicago.

Allen W. Phillips

14 Arturo Torres Rioseco, La poesia lírica mexicana, Santiago de Chile, -933 , p. 25 . 